\title{
Serpentes da área urbana de Cuiabá, Mato Grosso: aspectos ecológicos e acidentes ofídicos associados
}

\author{
Snakes from the urban area of Cuiabá, \\ $M$ ato Grosso: ecological aspects and \\ associated snakebites
}

Marcos André de Carvalho 1

Flávia Nogueira 2

\footnotetext{
1 Departamento de Biologia e Zoologia, Instituto de Biociências, Universidade Federal de Mato Grosso. Av. Fernando Correa s/no, Cuiabá, MT

78060-900, Brasil. mac@ufmt.cpd.br

2 Departamento de Botânica e Ecologia, Instituto de Biociências, Universidade Federal de Mato Grosso. Av. Fernando Correa s/no, Cuiabá, MT

78060-900, Brasil. ecouto@nutecnet.com.br
}

A bstract This study presents data on snakes recorded in the urban area of Cuiabá, Mato Grosso, Brazil. Sources of information included specimens captured by local residents (1986-1993) and turned over to the Mato Grosso Regional Ophiological Center (Normat), and data from the AntiVenom Information Center (Ciave), regarding urban snakebites (1988-1993). Thirty-seven species of snakes from 25 genera and three families were recorded. Diurnal and terrestrial habits predominated, as well as a diet based on amphibians and/or lizards. From a total of 307 snakebites recorded, some $56 \%$ were of no clinical importance, caused by non-venomous snakes, whereas $44 \%$ were clinically rel evant. Approximately $99 \%$ of the latter were attributed to vipers of the genus Bothrops, and especially the Bothrops moojeni and Bothrops neuwiedi species The colubrids Philodryas olfersii and Waglerophis merremii were probably responsible for most of the non-venomous snakebites.

Key words Snakes; SnakeBites; Urban Zones

Resumo São apresentadas informações sobre as serpentes da área urbana do Município de Cui abá, Mato Grosso, potencialmente causadoras de acidentes ofídi cos. As i nformações estão baseadas em exemplares doados por populares ao Núcleo de Ofiologia Regional de Mato Grosso (Normat) entre 1986 e 1993 e em regi stros efetuados pel o Centro de Informações Anti-Veneno (Ciave) entre 1988 e 1993, que não fazem referência ao animal causador. Foram catal ogadas 37 espécies de serpentes, em 25 gêneros e 3 famílias, com hábitos predomi nantemente diurnos, terrestres e com dietas baseadas em anfíbi os e/ou lagartos. Dentre os 307 aci dentes ofídi cos registrados, 56\% foram cau sad os por serpentes sem interesse médi co e $44 \%$ constituíram aci dentes de importância médica. Cerca de $99 \%$ dos aci dentes de importância médica foram atribuídos ao gênero Bothrops (Bothrops moojeni e Bothrops neuwiedi seriam as principais causadoras). Dentre as espéci es sem interesse médico, Philodryas olfersii e Waglerophis merremii provavelmente foram as princi pais responsáveis pela maior parte dos aci dentes.

Palavras-chave Cobras; Mordeduras de Cobra; Zonas Urbanas 


\section{Introdução}

Ainda nos dias de hoje os acidentes por animais peçonhentos constituem um problema de Saúde Pública para países em desenvolvimento, dada a incidência, a gravidade e as seqüelas deixadas no doente (Minton Jr., 1974).

Quanto aos acidentes ofídicos, Swaroop \& Grab (1954) (apud Minton Jr., 1974) estimaram a mortalidade, em nível mundial, em 30000 a 40000 mortes/ ano, assumindo a mortalidade em torno de $15 \%$, com uma incidência de 300000 picadas/ ano. As regiões mais atingidas são o sudeste da Ásia e a América Tropical. Dentre os países sul-americanos o Brasil é o que apresenta maior número de acidentes/ano (WHO, 1981). De janeiro de 1987 a fevereiro de 1988 o Ministério da Saúde foi notificado de cerca de 30724 casos de acidentes causados por serpentes no Brasil (MS, 1989).

A produção de soro antiofídico e os estudos epidemiológicos dos acidentes brasileiros tiveram início em São Paulo, com o médico Vital Brazil (Brazil, 1911). Desde então, tanto a produção de soro antiofídico quanto a produção de conhecimentos sobre ofidismo e ofiologia estiveram centrados na região Sudeste.

Para descentralizar a produção de conhecimentos e dar suporte às ações do Ministério da Saúde para atender às necessidades regionais, foram criados, a partir de 1986, os Núcleos de Ofiologia Regionais. Um deles, o Núcleo de Ofiologia Regional de Mato Grosso (Normat), está sediado em Cuiabá e é vinculado à Secretaria Estadual de Saúde. Também por volta de 1987 tiveram início em Cuiabá os trabal hos do Centro de Informações Anti-Veneno (Ciave). Este órgão, ligado ao Plano Nacional de Informações Tóxico-Farmacológicas, está vinculado ao Município de Cuiabá através do Pronto Socorro Municipal.

Assim, somente a partir de 1988, com a criação do Normat e do Ciave, é que se estabeleceram condições mais concretas para o estudo da fauna ofídica do Estado, principalmente daquelas espécies de interesse médico, e de estudos epidemiológicos relativos aos acidentes ofídicos e de outros animais peçonhentos. Tais estudos, além de revelar os principais causadores de acidentes, também fornecem dados que poderão ser utilizados em campanhas de prevenção de acidentes, notadamente na área urbana.

Considerando-se a extrema carência de informações sobre a composição da comunidade de serpentes da área urbana de Cuiabá, e considerando-se que nas fichas de registros de acidentes ofídicos urbanos realizados pelo Ciave não se encontram descritos os animais causadores, este trabal ho tem como objetivo verificar se as espécies coletadas por populares (e depositadas no Normat) poderiam ser as causadoras dos referidos acidentes. Procura, assim, subsidiar ações referentes à profilaxia e epidemiologia de acidentes, bem como aumentar o conhecimento sobre a fauna de serpentes do Centro-Oeste brasileiro.

\section{Área de estudo}

O Município de Cuiabá possui uma extensão territorial de $2730 \mathrm{Km}^{2}$ e está situado na porção centro-sul do Estado de Mato Grosso, no limite ocidental dos domínios do Cerrado e próximo à borda leste do Pantanal Mato-grossense, entre as coordenadas geográficas de $15010^{\prime}$ a $15 \circ$ $50^{\prime}$ S e 540 50' a 580 10' W (Ross \& Santos, 1982; Figura 1). A área urbana possui aproximadamente 530 ha e está localizada na porção sul do município, à margem esquerda do rio Cuiabá, afluente do rio Paraguai (Ross \& Santos, 1982).

O clima é do tipo Aw de Köppen, ou seja, tropical semi-úmido com temperatura média de $24 \circ$ a $26{ }^{\circ} \mathrm{C}$, com quatro a cinco meses secos e duas estações bem definidas: uma seca (outono-inverno) e uma chuvosa (primavera-verão), com índice pluviométrico anual de 1250 a $1500 \mathrm{~mm}$ (Maitelli, 1994). O relevo é suave, com predominância de colinas arredondadas eáreas aplainadas, de relevo plano a suavemente ondulado com declive inferior a 5\%. Também merecem destaque as áreas alagáveis, representadas por várzeas e embaciados, situadas principalmente na planície inundável do rio Cuiabá, e as áreas do seu dique marginal, que estão situadas entre a cal ha do rio e a planície de inundação (Castro Jr., 1990). Nos seus terrenos, na direção sul, iniciam-se os primeiros declives do Pantanal Mato-grossense. A cobertura vegetal é constituída por remanescentes de cerrado, cerradão, matas ciliares e por vegetação exóti$c a$, representada por frutíferas, plantas ornamentais e gramíneas, cultivadas nos quintais e praças da cidade. A vegetação nativa da região e os remanescentes de cerrado formam um verdadeiro cinturão em torno da área urbana de Cuiabá (Guarim Neto, 1991).

A partir da década de 70 , a cidade até então um tanto isolada das regiões mais desenvolvidas, começou a sofrer os impactos do "novo" modelo de desenvolvimento adotado no país no período. Assim, a região foi incorporada aos grandes projetos de desenvolvimento. Isto ocorreu de forma direta, com a construção de estradas (Projeto de Integração Nacional) e 
de forma indireta, pela colonização da Região Noroeste do país (Projeto Polonoroeste) e pela colonização do norte do Estado. Observou-se um aumento de cerca de $359 \%$ da população em apenas 30 anos. Como conseqüência imediata deste crescimento surgiram novos bairros periféricos, enquanto outros já existentes sofreram um "inchamento". Esta urbanização não planejada, segundo Castro Jr. (1990), permitiu a ocupação de áreas impróprias à habitação humana, como é o caso das áreas sujeitas a inundações periódicas (várzeas e embaciados), e das áreas degradadas pelas atividades de mineração. O crescimento, não planejado, aliado à especulação imobiliária, permitiu o surgimento de verdadeiras ilhas de vegetação nativa com diferentes graus de alterações antrópicas.

\section{Material e métodos}

Para saber se as espécies coletadas por populares poderiam ser as causadoras dos acidentes ofídicos registrados, foram analisados espécimes oriundos da área urbana de Cuiabá, Mato Grosso, depositados na coleção de referência do Normat e aqueles coligidos por Christine Strüssmann, depositados na coleção de vertebrados do Instituto de Biociências da Universidade Federal de Mato Grosso, durante o período de 1986 a 1993. Foram analisadas também as fichas de registro de casos de acidentes ofídicos elaboradas pelo Ciave durante o período de 1988 a 1993.

A análise conjunta destes dados permite que se atinja o objetivo proposto, desde que se parta do princípio de que os acidentes ocorrem pelo contato ocasional entre algumas espécies de serpentes e populares, e, também, que apenas como conseqüência de encontros casuais é que os populares coletam organismos e os levam ao núcleo de ofiologia. Pode-se portanto considerar que se trata do mesmo conjunto de serpentes. Cabe ressaltar que a população, em nenhum momento, foi estimulada através de campanhas para coletar animais. A coleta e envio ao núcleo foi totalmente espontânea no período.

A identificação das espécies registradas pelo Normat foi realizada, em sua maioria, pelos autores, com base na literatura corrente (Peters \& Donoso-Barros, 1970; Thomas, 1976; Dixon, 1989, 1991; Dixon et al., 1993; Myers \& Cadle, 1994). Uma espécie (Chironi us quadricarinatus) foi identificada por avistamento (Ivan Sazima, comunicação pessoal e fotografias) e outras duas espécies apresentaram problemas taxonômicos.

\section{Figura 1}

Área de estudo: Município de Cuiabá, Mato Grosso, com destaque para a área urbana.

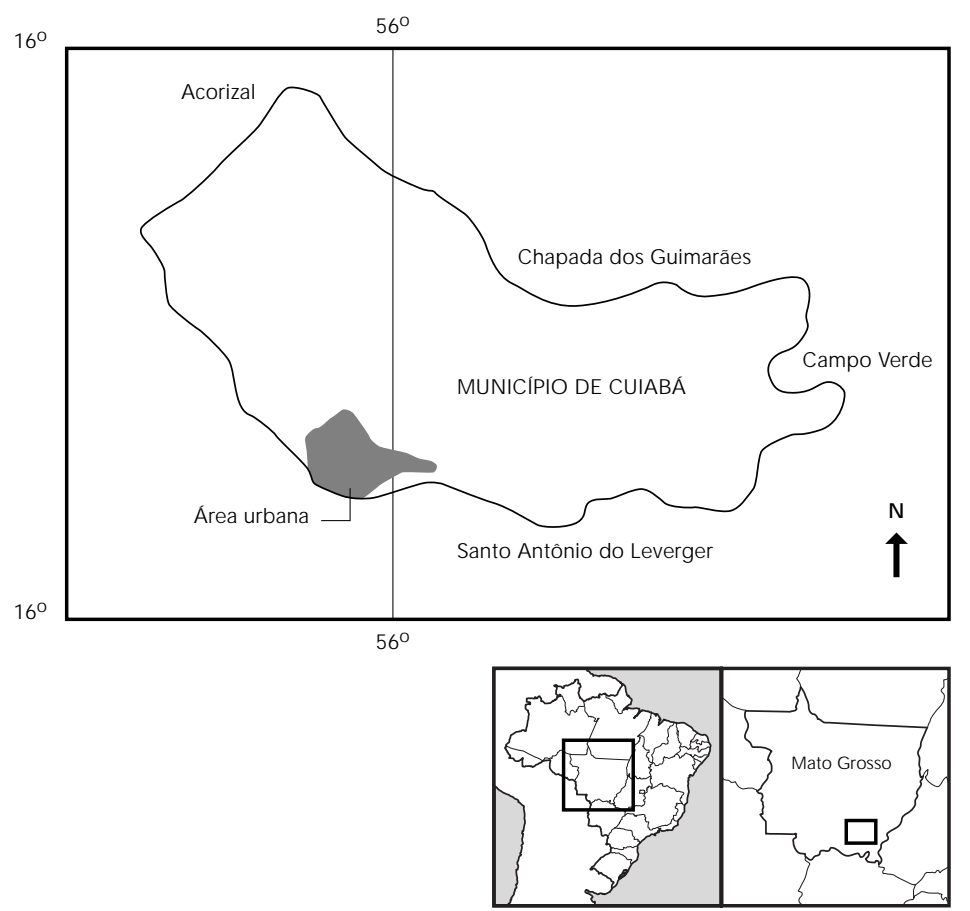

Org. Flávia Nogueira. Adaptado de Maitelli, 1994.

Para cada espécie foram compilados os aspectos ecológicos relacionados, isto é, utilização do substrato (serpentes terrestres, aquáticas, semi-aquáticas, semi-arbóreas, fossórias e criptozóicas), período de atividade (diurnas, noturnas) e dieta. A descrição de tais características se baseou em registros bibliográficos, complementados por observações diretas no campo e, em alguns casos, na análise do conteúdo estomacal, intestinal e de fezes.

Os dados relativos aos acidentes ofídicos registrados pelo Ciave têm como base as informações provenientes das fichas de registro, que totalizaram 1279 casos no período de 1988 a 1993. As fichas traziam informações sobre horário e local em que ocorreram os acidentes e, em alguns casos, sobre o provável causador. Foram considerados os acidentes ocorridos na área urbana e rural do município de Cuiabá (para comparação), desde que houvesse certeza quanto à sua ocorrência em residências ou em locais próximos a elas. Desta forma foram selecionados 307 casos. A identificação do animal agressor (em nível genérico) e o diagnóstico do acidente foram efetuados por médico 
Tabela 1

Relação das famílias com as respectivas espécies de serpentes registradas para a área urbana de Cuiabá, Mato Grosso.

Espécies

Boidae

Boa constrictor (Linnaeus, 1758)

Epicrates cenchria (Linnaeus, 1758)

Eunectes murinus (Linnaeus, 1758)

\section{Colubridae}

Apostolepis cf. rondoni Amaral, 1925

Chironius flavolineatus (Boettger, 1885)

Chironius laurenti Dixon, Wiest \& Cei, 1993

Chironius quadricarinatus (Boie, 1827)

Helicops leopardinus (Schlegel,1837)

Hydrodynastes gigas (Duméril, Bibron \& Duméril, 1854)

Leptophis ahaetulla (Linnaeus, 1758)

Liophis almadensis (Wagler, 1824)

Liophis cobella (Linnaeus, 1758)

Liophis meridionalis (Schenkel, 1901)

Liophis poecilogyrus (Wied, 1824)

Liophis reginae (Linnaeus, 1758)

Mastigodryas bifossatus (Raddi, 1820)

Mastigodryas boddaerti (Sentzen, 1796)

Oxyrhopus rhombifer Duméril, Bibron \& Duméril, 1854

Oxyrhopus aff. trigeminus Duméril, Bibron \& Duméril, 1854

Phalotris tricolor Cope, 1861

Philodryas matogrossensis Koslowsky, 1898

Philodryas nattereri (Steindachner, 1870)

Philodryas olfersii (Lichtenstein, 1823)

Phimophis guerini (Duméril, Bibron e Duméril, 1854)

Psomophis genimaculatus (Boetger,1885)

Pseudablabes agassizii (J an, 1863)

Pseudoboa nigra (Duméril, Bibron e Duméril, 1854)

Pseudoeryx plicatilis (Linnaeus, 1758)

Sibynomorphus turgidus (Cope, 1868)

Taeniophalus occipitalis (J an, 1863)

Tantilla melanocephala (Linnaeus, 1758)

Waglerophis merremii (Wagler, 1824)

Xenopholis cf. undulatus (J ensen, 1900)

Viperidae

Bothrops moojeni Hoge, 1966

Bothrops neuwiedi Wagler, 1824

Crotalus durissus Linnaeus 1758 plantonista, com base nos sintomas apresentados pelos acidentados e, nos poucos casos em que o paciente coletou a serpente causadora do acidente, também pela análise do animal agressor.

Cabe ressaltar que o termo acidente de importância médica será utilizado para denominar acidentes que necessitam de atendimento médico. $\mathrm{O}$ acidente ofídico de importância médica pode ser classificado, quanto à gravidade, em leve, moderado e grave (MS, 1988).

O conceito de animal peçonhento seguido no presente estudo é o mesmo sugerido por Freitas (1991). De acordo com este conceito, um animal peçonhento é aquele que possui glândulas produtoras de toxina, com ductos excretores, associadas ou não a um aparato inoculador. Este conceito desvincula o termo animal peçonhento do termo animal de interesse médico, ou seja, nem todos os animais peçonhentos causam acidentes de importância médica, quer pela baixa toxicidade da peçonha para o organismo humano, quer pela incapacidade de inoculação. Portanto, ser um animal peçonhento não significa necessariamente ser um animal de interesse médico. Como nem todas as serpentes peçonhentas causam acidentes de interesse médico, foram utilizados os seguintes termos:

- serpentes de interesse médico (DIM), para aquelas serpentes peçonhentas causadoras de acidentes de importância médica (leves, moderados, graves);

- serpentes sem interesse médico (SIM), para serpentes não peçonhentas, para aquelas peçonhentas que não causam acidentes ou que causam acidentes sem importância médica.

\section{Resultados}

No período de 1986 a 1993 foram registradas para a área urbana de Cuiabá 37 espécies de serpentes distribuídas em 25 gêneros e três famílias (Tabela 1), totalizando 213 indivíduos.

Dentre as dez espécies com maior número de registros (Tabela 2), cinco se destacam quanto à abundância: Liophis poecilogyrus, Si bynomorphus turgidus, Waglerophis merremi i, Liophis almadensis e Philodryas olfersi i. Do total de serpentes registradas, três espécies, ou $8,6 \%$ do total das espécies, e 13 indivíduos, ou $6,1 \%$ do total dos indivíduos registrados, são de interesse médico, ou seja, podem causar acidentes ofídicos.

Com relação aos aspectos ecológicos (Tabela 3), observa-se que o conjunto de espécies registradas para a área urbana de Cuiabá é com- 
posto por $71,5 \%$ de espécies terrestres, cerca de $14 \%$ de semi-arbóreas, $11 \%$ de aquáticas e semi-aquáticas e 3\% de fossórias. Quanto ao período de atividade, $57 \%$ das espécies são diurnas, $20 \%$ noturnas, $20 \%$ diurnas/ noturnas. Para uma espécie de hábito criptozóico (Xenopholis cf. undulatus) não foi possível determinar o período de atividade. Em relação ao número de indivíduos, $45 \%$ são de hábito diurno, $27 \%$ de hábito noturno, $28 \%$ diurno/ noturno e para um indivíduo criptozóico $(0,5 \%)$ não foi determinado o período de atividade. Cerca de $25 \%$ do número total das espécies alimentamse principalmente de anfíbios e/ ou lagartos, $18 \%$ além de anfíbios e lagartos também consomem pequenos mamíferos. Serpentes que consomem peixes e aquelas que consomem artrópodes estão representadas por $6 \%$, no grupo de espécies registradas, e aquelas que se alimentam principalmente de pequenos roedores representam apenas 3\% do total das espécies. Embora Sibynomorphus turgidus seja a única espécie que consome exclusivamente moluscos (3\% do número total de espécies), ela representa $10 \%$ do total de indivíduos registrados.

Dos 307 acidentes ofídicos registrados pelo Ciave no período de 1988 a 1993, para o Município de Cuiabá, 136 acidentes (44\%) foram registrados para a área urbana, e 171(56\%) para a área rural. Quanto à importância médica, 176 acidentes (57\%) mereceram atenção, sendo que a área urbana contribuiu com cerca de $15 \%$ e a rural com cerca de $42 \%$ (Figura 2). Dos 136 acidentes registrados para a área urbana de Cuiabá, cerca de 35\% são de importância médica. No entanto, apenas $8 \%$ das espécies e $4 \%$ dos indivíduos registrados podem causar acidentes de importância médica (Figura 3).

Quanto ao local, 85\% dos acidentes sem importância médica e $49 \%$ dos acidentes de importância médica ocorreram nas residências ou nas adjacências, o que representa cerca de $73 \%$ do total dos acidentes registrados para a área urbana de Cuiabá (Figura 4).

Com respeito ao horário de ocorrência dos acidentes na área urbana, 69 casos sem importância médica e 31 causados por serpentes de interesse médico ocorreram no período diurno, entre 6:00 e 18:00 horas (Figura 5).

Dos 47 acidentes de importância médica registrados para a área urbana, 46 (99\%) foram atribuídos ao gênero Bothrops (acidente botrópico) e apenas 1 ao gênero Crotalus (acidente crotálico); para a área rural, 124 e 5 acidentes foram atribuídos ao gênero Bothrops e ao gênero Crotalus, respectivamente (Figura 6). Dos 136 registros de acidentes ofídicos sem impor-
Tabela 2

Relação das serpentes em ordem decrescente de sua abundância relativa em porcentagem, com indicação daquelas que são de interesse médico.

\begin{tabular}{|c|c|c|c|}
\hline Espécies & n Indivíduos & $\%$ do total & Interesse médico \\
\hline Liophis poecilogyrus & 30 & 14.1 & $\mathrm{~N}$ \\
\hline Sibynomorphus turgidus & 21 & 9.8 & $\mathrm{~N}$ \\
\hline Waglerophis merremii & 17 & 8.0 & $\mathrm{~N}$ \\
\hline Liophis almadensis & 15 & 7.0 & $\mathrm{~N}$ \\
\hline Philodryas olfersii & 12 & 5.6 & $\mathrm{~N}^{*}$ \\
\hline Phalotris tricolor & 09 & 4.2 & $\mathrm{~N}$ \\
\hline Mastigodryas boddaerti & 08 & 3.7 & $\mathrm{~N}$ \\
\hline Oxyrhopus cf. trigeminus & 08 & 3.7 & $\mathrm{~N}$ \\
\hline Bothrops neuwiedi & 07 & 3.3 & $\mathrm{~S}$ \\
\hline Eunectes murinus & 07 & 3.3 & $\mathrm{~N}$ \\
\hline Psomophis genimaculatus & 07 & 3.3 & $\mathrm{~N}$ \\
\hline Boa constrictor & 06 & 2.8 & $\mathrm{~N}$ \\
\hline Helicops leopardinus & 06 & 2.8 & $\mathrm{~N}$ \\
\hline Pseudoboa nigra & 06 & 2.8 & $\mathrm{~N}$ \\
\hline Chironius laurenti & 05 & 2.3 & $\mathrm{~N}$ \\
\hline Taeniophalus occipitalis & 05 & 2.3 & $\mathrm{~N}$ \\
\hline Hydrodynastes gigas & 05 & 2.3 & $\mathrm{~N}$ \\
\hline Bothrops moojeni & 05 & 2.3 & $\mathrm{~S}$ \\
\hline Liophis meridionalis & 04 & 1.9 & $\mathrm{~N}$ \\
\hline Liophis reginae & 04 & 1.9 & $\mathrm{~N}$ \\
\hline Oxyrhopus rhombifer & 04 & 1.9 & $\mathrm{~N}$ \\
\hline Epicrates cenchria & 03 & 1.4 & $\mathrm{~N}$ \\
\hline Phimophis guerini & 03 & 1.4 & $\mathrm{~N}$ \\
\hline Liophis cobellus & 02 & 0.9 & $\mathrm{~N}$ \\
\hline Mastigodryas bifossatus & 02 & 0.9 & $\mathrm{~N}$ \\
\hline Philodryas nattereri & 02 & 0.9 & $\mathrm{~N}$ \\
\hline Tantilla melanocephala & 02 & 0.9 & $\mathrm{~N}$ \\
\hline Apostoleps cf. rondoni & 01 & 0.5 & $\mathrm{~N}$ \\
\hline Chironius flavolineatus & 01 & 0.5 & $\mathrm{~N}$ \\
\hline Chironius quadricarinatus & 01 & 0.5 & $\mathrm{~N}$ \\
\hline Crotalus durissus & 01 & 0.5 & $\mathrm{~S}$ \\
\hline Leptophis ahaetulla & 01 & 0.5 & $\mathrm{~N}$ \\
\hline Philodryas mattogrossensis & 01 & 0.5 & $\mathrm{~N}$ \\
\hline Pseudablabes agassizii & 01 & 0.5 & $\mathrm{~N}$ \\
\hline Pseudoeryx plicatilis & 01 & 0.5 & $\mathrm{~N}$ \\
\hline Xenopholis cf. undulatus & 01 & 0.5 & $\mathrm{~N}$ \\
\hline Total & 213 & 100.0 & 3 \\
\hline
\end{tabular}

* Neste estudo a espécie não foi considerada de interesse médico por não constar formalmente nas citações do M inistério da Saúde (MS, 1988), embora Bucarechti et al. (1993) recomendem sua inclusão na relação das serpentes de interesse médico, por causar acidentes semelhantes aos acidentes botrópicos leves. 
Tabela 3

Serpentes da área urbana de Cuiabá e alguns dados sobre sua história natural. Letras minúsculas indicam observação única ou de menor importância na categoria; a maior parte dos dados são provenientes da literatura.

\begin{tabular}{|c|c|c|c|}
\hline Espécies & Substrato & Atividade & Dieta \\
\hline Boa constrictor & $\mathrm{TE}, \operatorname{sb}(1,2)$ & $\mathrm{D} / \mathrm{N}$ & av, MA, (AV,la) \\
\hline Epicrates cenchria & $\mathrm{TE}, \mathrm{sb}$ & $\mathrm{D} / \mathrm{N}$ & $M A,(a v, l a)$ \\
\hline Eunectes murinus & SA & $\mathrm{D} / \mathrm{N}$ & $(\mathrm{MA}, \mathrm{AV}, \mathrm{VE})$ \\
\hline Apostoleps cf. rondoni & $(\mathrm{FO})$ & $(D / N)$ & $(A B, I N)$ \\
\hline Chironius flavolineatus & SB & $\mathrm{D}$ & an \\
\hline Chironius laurenti & SB & $\mathrm{D}$ & AN \\
\hline Chironius quadricarinatus & $\mathrm{SB}$ & $\mathrm{D}$ & $(\mathrm{AN})$ \\
\hline Helicops leopardinus & $\mathrm{AQ}$ & $N, d$ & $(\mathrm{PE}, \mathrm{an})$ \\
\hline Hydrodynastes gigas & SA & $\mathrm{D}$ & $(\mathrm{PE}, \mathrm{AN}, \mathrm{ma}, \mathrm{ca})$ \\
\hline Leptophis ahaetulla & SB & $\mathrm{D}$ & $(\mathrm{AN}, \mathrm{la})$ \\
\hline Liophis almadensis & TE & $\mathrm{D}$ & AN \\
\hline Liophis cobellus & te, (TE) & $\mathrm{D}$ & (an,la) \\
\hline Liophis meridionalis & TE & $\mathrm{D}$ & (an) \\
\hline Liophis poecilogyrus & te, (TE) & $\mathrm{D} / \mathrm{N}$ & AN \\
\hline Liophis reginae & TE & $\mathrm{D}$ & $(\mathrm{AN})$ \\
\hline Mastigodryas bifossatus & TE & $\mathrm{D}$ & $(\mathrm{AN}, \mathrm{LA}, \mathrm{MA})$ \\
\hline Mastigodryas boddaerti & SB & $\mathrm{D}$ & (an,la,ma) \\
\hline Oxyrhopus rhombifer & TE & $\mathrm{N}$ & $(a n, l a)$ \\
\hline Oxyrhopus aff. trigeminus & TE & $\mathrm{N}$ & la,ma, (LA,ov) \\
\hline Phalotris tricolor & FO & $\mathrm{N}$ & $(a b)$ \\
\hline Philodryas matogrossensis & te, (sb) & $\mathrm{D}$ & (an,la) \\
\hline Philodryas nattereri & TE & $\mathrm{D}$ & la,ma,(an,av) \\
\hline Philodryas olfersii & TE & $\mathrm{D}$ & ma,(an,la,av) \\
\hline Phimophis guerini & te & $\mathrm{n}$ & $?$ \\
\hline Psomophis genimaculatus & $\mathrm{TE}, \mathrm{sb}$ & $\mathrm{D}$ & an, (la) \\
\hline Pseudablabes agassizii & $\mathrm{TE}$ & $\mathrm{D}$ & $(A R)$ \\
\hline Pseudoboa nigra & TE & $\mathrm{N}$ & $\mathrm{ma}(\mathrm{LA}, \mathrm{ov})$ \\
\hline Pseudoeryx plicatilis & $\mathrm{AQ}$ & $d$ & $(\mathrm{PE})$ \\
\hline Sibynomorphus turgidus & TE & $\mathrm{N}$ & MO \\
\hline Taeniophalus occipitlis & TE & $\mathrm{D}$ & an,la \\
\hline Tantilla melanocephala & TE & $\mathrm{D}, \mathrm{n}$ & $(A R)$ \\
\hline Waglerophis merremii & $\mathrm{TE}$ & $\mathrm{D}, \mathrm{n}$ & AN \\
\hline Xenopholis cf. undulatus & $C R$ & $?$ & (an) \\
\hline Bothrops moojeni & TE & $\mathrm{D} / \mathrm{N}$ & an,la,ma(se,VE) \\
\hline Bothrops neuwiedi & TE & $\mathrm{D} / \mathrm{N}$ & ma, (an, MA) \\
\hline Crotalus durissus & TE & $\mathrm{D} / \mathrm{N}$ & $\mathrm{ma},(\mathrm{MA})$ \\
\hline
\end{tabular}

$A B$, anfisbenídeos; $A N$, anfíbios; $A Q$, aquáticas; $A R$, artrópodes; $A V$, aves; CA, carcaça; CR, crípticas; D, diurnas; FO, fossórias; LA, lagartos; M O, moluscos (lesmas); $M A$, mamíferos; $N$, noturnas; $O V$, ovos (de répteis); $P E$, peixes:

$\mathrm{SA}$, semi-aquáticas; $\mathrm{SB}$, semi-arbóreas; $\mathrm{SE}$, serpentes; $\mathrm{TE}$, terrestres;

$\mathrm{VE}$, outros vertebrados que não peixes. tância médica, apenas 15\% fizeram menção à serpente causadora do acidente. Destes, $71 \%$ foram atribuídos à "cobra-verde", provavelmente Philodryas ol fersii.

\section{Discussão}

Segundo Sazima (1988), o conhecimento do comportamento defensivo das serpentes e dos aspectos ecológicos relacionados às mesmas pode ser utilizado para prever a ocorrência de acidentes ofídicos de importância médica. Da mesma forma estes conhecimentos podem ser utilizados para identificar dentre as serpentes sem interesse médico, aquelas potenciais causadoras de acidentes ofídicos.

O tipo de comportamento adotado pela serpente, principalmente as táticas defensivas diante de um suposto agressor, certamente é o principal fator que determina o acidente ofídico. As táticas defensivas podem variar, no entanto, conforme o substrato utilizado e o período de atividade. Conseqüentemente, dependendo do substrato e do período de atividade, a serpente terá que enfrentar diferentes tipos de predadores. Por exemplo, serpentes de hábitos terrestres e semi-arbóreos, com atividade diurna, tendem a ser predadas por um maior número de animais orientados visualmente do que serpentes de hábitos fossórios ou aquelas de hábitos noturnos. Como o homem é um animal orientado visualmente, as táticas defensivas utilizadas por serpentes de hábitos terrestres e diurnas tendem a ser mais evidentes do que aquelas observadas para serpentes de hábitos fossórios e daquel as eminentemente noturnas. Geral mente para as serpentes de hábitos terrestres ou semi-arbóreos eminentemente diurnas, a imobilidade, fuga e ações relativas à intimidação, nesta ordem, são as táticas mais usadas quando do encontro da serpente (mesmo daquelas peçonhentas) com um suposto predador (agressor) (Sazima, 1988; Sazima \& Haddad, 1992; Strüssmann, 1992; Martins, 1994).

Quando um suposto agressor atinge a distância mínima de segurança, al gumas serpentes podem utilizar táticas de defesa para a intimidação, como por exemplo, achatamento dorso-ventral do corpo ou apenas da região do pescoço seguida ou não da elevação da cabeça, triangulação da cabeça, achatamento lateral com dilatação da região gular, retração da parte anterior do corpo fazendo "S"(armar bote), podendo escancarar a boca, bufar ou desferir "falsos botes". Se o agressor ignorar estas táticas e ultrapassar a distância mínima de segu- 
rança, então a serpente pode picar ou morder. Quando as serpentes mordem ou picam tornam-se mais expostas aos danos causados pela presa ou pelo predador, pois sua única arma de ataque são os dentes. Portanto, certamente a mordida ou a picada devem ser os últimos recursos utilizados para a defesa. Entretanto, algumas serpentes, mesmo quando capturadas, não procuram morder. Por exemplo, todos os indivíduos de Liophis poecilogyrus, Psomophis genimaculatus e Taeniophalus occipitalis coletados ou recebidos não procuraram morder quando manuseados.

A imobilidade aliada à coloração pode tornar a serpente imperceptível aos predadores orientados visualmente. No entanto, a coloração de algumas serpentes, além de camuflar, pode ser usada para imitar o padrão de colorido de serpentes peçonhentas. Tais serpentes ao serem acuadas também podem adotar táticas defensivas de intimidação. Por exemplo a serpente Waglerophis merremi (não peçonhenta) pode apresentar padrões de coloração semeIhantes às serpentes do gênero Bothrops ou mesmo do gênero Crotalus, ambas de interesse médico, e quando acuada pode achatar o corpo dorsoventralmente, escancarar a boca e desferir botes (observação pessoal).

Das serpentes registradas no Normat, 38,5\% dos indivíduos sem interesse médico (representando cerca de $44 \%$ das espécies) apresentam comportamento de defesa agressivo, isto é, aqueles que incluiriam entre as táticas de defesa fazer " $S$ " com o pescoço, desferir botes e morder.

Embora o número de acidentes ofídicos sem importância médica supere o número de acidentes de importância médica, a diferença observada entre estes números não parece ser tão significativa quando comparada à diferença entre o número de espécies e principalmente de indivíduos de serpentes de interesse médico e aqueles relativos a serpentes sem interesse médico (Figura 2). É importante ressaltar que no presente trabalho a abundância relativa está diretamente relacionada à freqüência de encontros entre serpentes e os habitantes da área urbana.

A maior parte dos acidentes registrados para a área urbana (73\%) ocorreu nas resi dências ou adjacências (Figura 4).O encontro dos residentes da área urbana com serpentes ocorre de forma freqüente não só devido ao el evado número de habitantes, principalmente na periferia, como também devido ao tipo de atividade que estes desenvolvem. O maior número de acidentes sem importância médica registrados para a área urbana de Cuiabá em relação à área
Figura 2

Acidentes registrados para a área urbana e rural do Município de Cuiabá, pelo Ciave no período de 1988 a 1993, segundo a importância médica. D.I.M. = acidentes de importância médica; S.I.M. = acidentes sem importância médica.

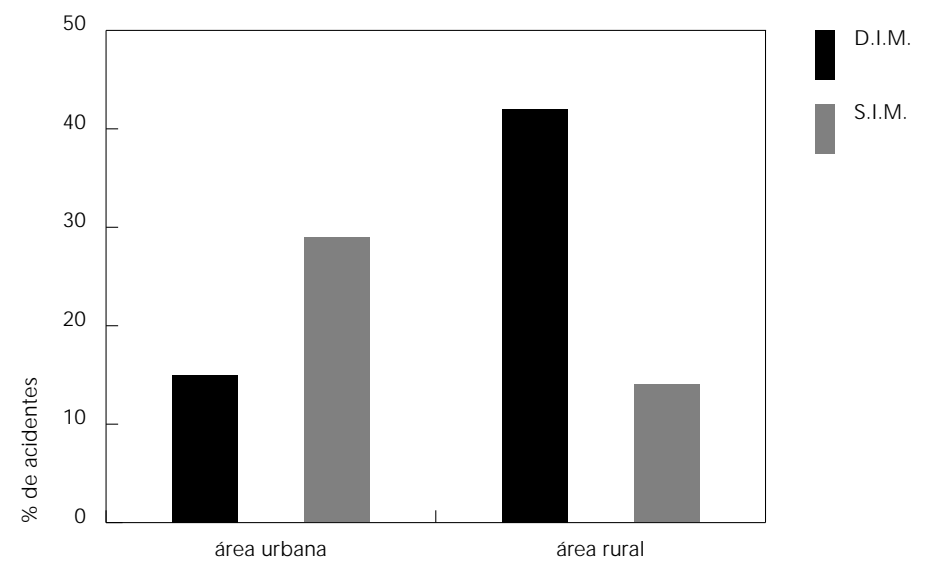

Figura 3

Acidentes ofídicos registrados pelo Ciave no período de 1988 a 1993, e de espécies e indivíduos de serpentes, registrados para a área urbana de Cuiabá, Mato Grosso, no período de 1986 a 1993, segundo o interesse médico.

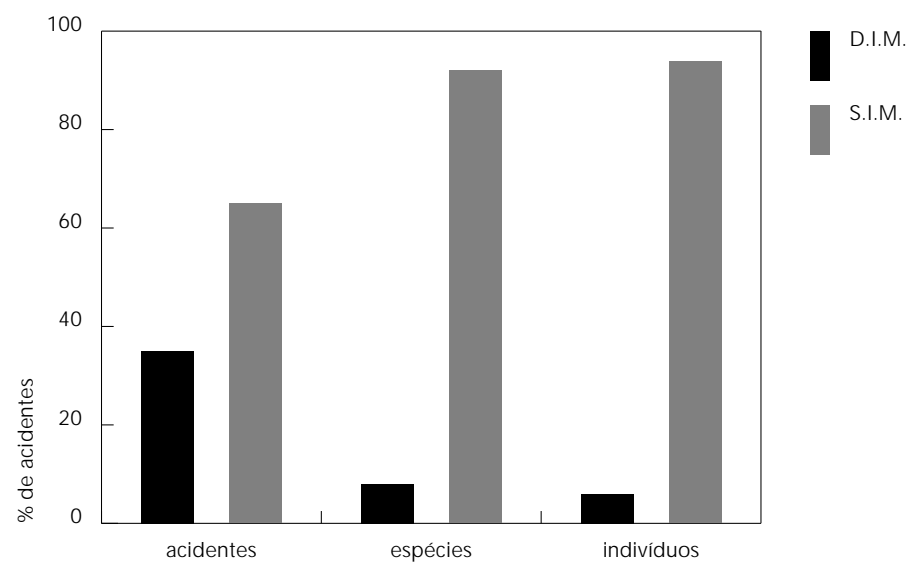




\section{Figura 4}

Porcentagem de acidentes ofídicos registrados pelo Ciave no período de 1988 a 1993 para a área urbana de Cuiabá, Mato Grosso, segundo o local de ocorrência e a importância médica. D.I.M. = acidentes de importância médica; S.I.M. = acidentes sem importância médica.

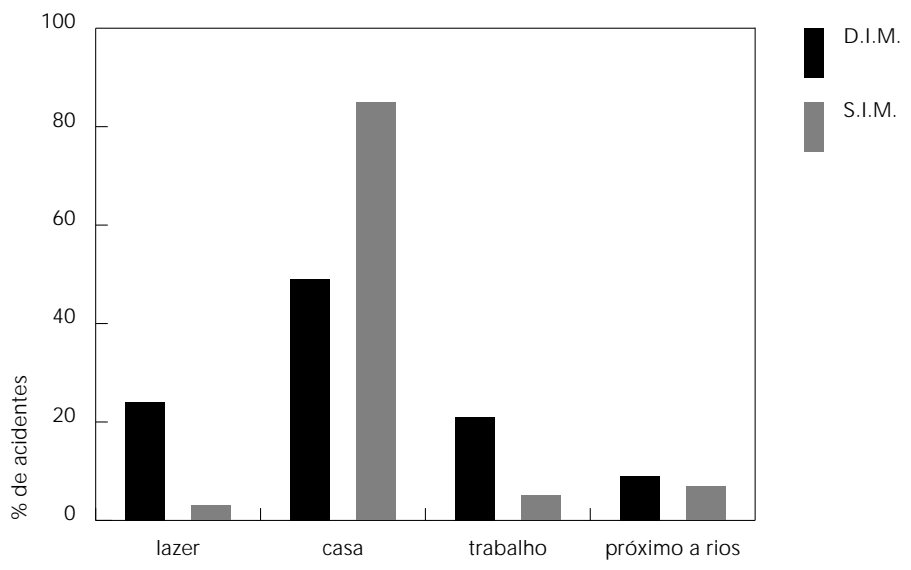

Figura 5

Número de acidentes ofídicos, registrados pelo Ciave no período de 1988 a 1993, para a área urbana de Cuiabá, Mato Grosso, segundo o horário de ocorrência e a importãncia médica. D.I.M. = acidentes de importância médica; S.I.M. = acidentes sem importância médica.

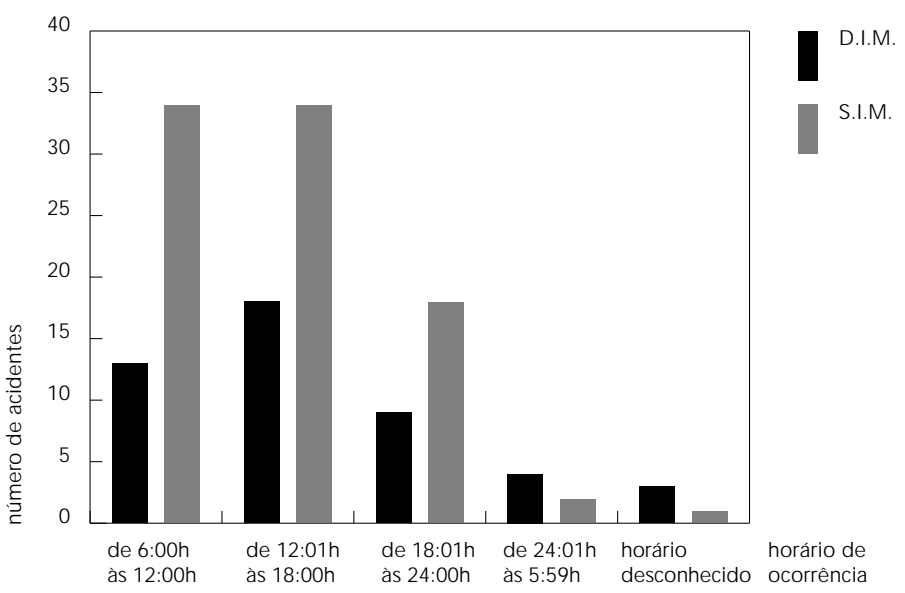

rural (Figura 2) provavelmente deriva do fato de que talvez haja maior susceptibilidade das espécies de interesse médico registradas às alterações ambientais relacionadas à urbanização.

Entre as serpentes supostamente causadoras de acidentes, Philodryas olfersi i (cobra-cipó-verde), a quinta serpente mais abundante do grupo registrado para Cuiabá parece ser a mais importante. Além de apresentar uma maior abundância relativa, al guns aspectos comportamentais provavel mente também contribuem para o contato e conseqüentemente, para a ocorrência de acidentes envolvendo a referida espécie. Caracteristicamente, forrageia de forma ativa por entre a vegetação ou no chão à procura de pequenos vertebrados, principalmente pequenos roedores, nas horas mais quentes do dia. À noite, ou nos períodos mais frios, abriga-se nas partes altas da vegetação ou até mesmo em habitações humanas (Sazima \& Haddad, 1992). Desta forma, seu comportamento de forrageador ativo nas horas mais quentes do dia faz com que esta serpente freqüentemente penetre nos quintais ou mesmo no interior das residências (principalmente daquelas próximas a áreas com vegetação nativa), no período em que os habitantes da área urbana também estão em atividade, aumentando as chances de contato entre a serpente e o homem, e conseqüentemente, os acidentes. Cerca de $79 \%$ dos acidentes ofídicos sem importância médica, registrados pelo Ciave no período de 1988 a 1993 para a área urbana de Cuiabá, ocorreram em residências ou em suas adjacências (Figura 4). Ao primeiro contato com o homem, esta serpente procura fugir, mas quando acuada ou manuseada pode morder e inocular peçonha com facilidade (obs. pessoal).

Dos acidentes sem importância médica em que os pacientes fizeram menção à serpente causadora (apenas 15\% do total de acidentes sem importância médica), 71\% foram atribuídos à "cobra-verde" (Philodryas ol fersii). Dentre as serpentes registradas para a área urbana, P. olfersi i é a única que apresenta a cor verde. Isto indica que, em Cuiabá esta espécie realmente não provoca acidente que mereça atenção médica, embora em outras regiões esta espécie provoque acidentes semelhantes a acidentes botrópicos leves (Silva \& Buononato, 1983/ 84; Bucarechti et al.,1993).

A serpente Waglerophis merremi (boipeva, capitão-do-campo, boca-de-capanga), a terceira mais abundante do grupo de espécies registradas, é a mais abundante dentre as supostamente causadoras de acidente ofídicos sem importância médica. No entanto não parece 
causar tantos acidentes quanto Philodryas olfersi i. Apenas dois, 9,5\% do total de acidentes sem importância médica, foram atribuídos à "boipeva" (Waglerophis merremi). Esta serpente de hábito eminentemente terrestre, forrageia durante o dia a procura de anfíbios, principalmente sapos (Bufo paracnemis). Quando ameaçada, achata o corpo dorso-ventralmente, podendo também escancarar a boca e/ ou desferir botes. Quando acuada ou capturada morde com facilidade. Geralmente os habitantes a confundem com serpentes de interesse médico, tais como Bothrops moojeni (jararaca), Bothrops neuwiedi (jararaca-pintada) ou mesmo com Crotalus durissus (cascavel). Todos os indivíduos desta espécie doados pelos habitantes da área urbana foram confundidos com jararacas ou com cascavéis, e este fato ilustra a dificuldade de pessoas leigas em distinguir esta espécie daquel as de interesse médico. Portanto, o nome boipeva (do tupi-guarani =cobra-chata) ou jararaca, nome utilizado na região de Cuiabá, podem referir-se tanto às espécies do gênero Bothrops quanto à espécie Waglerophis merremi. Embora os nomes vul gares utilizados para várias espécies de serpentes sejam pouco confiáveis, presumimos que os acidentes sem importância médica, ou seja destituidos de qualquer sintoma de envenenamento, ocorridos na área urbana e atribuidos a "boipeva" tenham sido causados por Waglerophis merremii. Esta serpente, amplamente distribuída na área de cerrado, parece que também esteve amplamente distribuída na área urbana, mas atualmente talvez ocorra somente em áreas restritas onde ocorrem anfíbios terrestres como sapos (principalmente Bufo paracnemis) e rãs (Leptodactylus).

A diferença entre número de espécies e indivíduos de serpentes de interesse médico e aqueles de serpentes sem interesse médico é proporcionalmente muito menor que a diferença entre o número de acidentes ofídicos de importância médica e aqueles sem importância médica. Portanto, embora em menor número (de espécies e de indivíduos), as serpentes de interesse médico (Tabela 1) causam mais acidentes do que as serpentes sem interesse médico. Desta forma, pode-se concluir que do contato, mesmo que pouco freqüente, entre as serpentes de interesse médico e habitantes da área urbana, certamente poderá ocorrer um acidente ofídico. Provavelmente o fato de os viperídeos (causadores de acidentes ofídicos de importância médica) serem generalistas e rodentívoros favorece a exploração de ambientes periantrópicos propiciando assim o encontro entre serpente e o homem. Portanto, este fato,
Figura 6

Porcentagem do número de acidentes crotálicos e botrópicos, registrados pelo Ciave, no período de 1988 a 1993, para a área urbana e área rural do Município de Cuiabá, Mato Grosso.

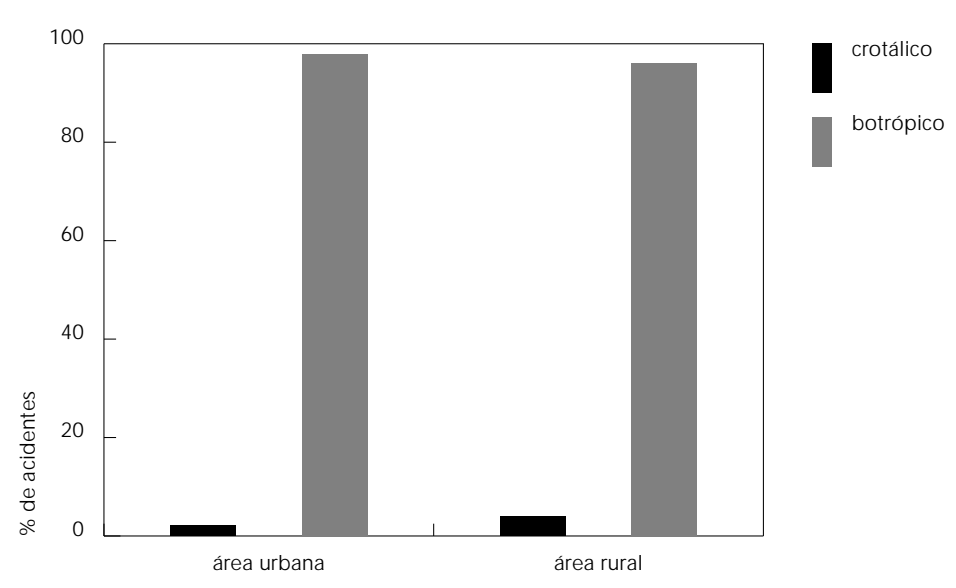

aliado às atividades relacionadas à limpeza de quintais, hortas ou chácaras, desenvolvidos pelos habitantes da área urbana nos bairros mais periféricos e naqueles próximos às áreas extensas pouco alteradas (por exemplo, matas ciliares, áreas alagáveis e ilhas de vegetação nativa) contribui para a freqüente ocorrência dos acidentes ofídicos de importância médica observados para os bairros mais periféricos da área urbana.

As serpentes de interesse médico registradas para a área urbana de Cuiabá também apresentam táticas de defesa envolvendo imobilização, fuga, retração da parte anterior do corpo, formando uma curva sigmóide (armar "bote") e projeção do corpo em direção ao suposto agressor (dar "botes"), semelhantes às observadas para Bothrops jararaca, espécie de ampla ocorrência na região sudeste da América do Sul (Sazima, 1988, 1989, 1991). Tanto as espécies do gênero Bothrops quanto as do gênero Crotalus podem também advertir vibrando vigorosamente a cauda. Esta suposta advertência é muito mais eficaz nas espécies do gênero Crotalus, pois ao vibrar a cauda produzem um som característico de "maracas", graças a um crepitáculo ou "chocal ho" presente na extremidade da cauda.

A serpente Bothrops neuwiedi (jararaca-pintada) foi a serpente de interesse médico que apresentou o maior número de registros para a área urbana. Esta espécie possui hábitos terrestres e embora possa ser encontrada em ativida- 
de durante o dia, a atividade noturna parece prevalecer. Durante o dia geralmente é encontrada em abrigos (buracos, sob pedras ou paus) e, possivelmente, os habitantes entram em contato com a mesma durante o dia, em atividades relativas à limpeza de quintais, hortas ou terrenos baldios, locais propícios à existência de abrigos. Esta serpente parece mais irritadiça do que as outras duas espécies de interesse médico, e, quando ameaçada, retrai a parte anterior do corpo e desfere vários "botes" seguidos.

Bothrops moojeni (jararaca, caiçaca, baetão) possui hábito terrestre e geralmente está em atividade durante o período noturno. Seus principais alimentos, quando adulta, são pequenos roedores e anfíbios, e quando filhote, alimenta-se principalmente de anfíbios e de pequenos lagartos (observação pessoal). Esta mudança ontogenética no hábito alimentar parece ser acompanhada também pela mudança na composição da peçonha: os acidentes ofídicos causados por filhotes desta espécie parecem ser diferentes, quanto aos sintomas apresentados, daqueles causados por serpentes adultas (Kouyoumdjian \& Polizelli, 1989; Ribeiro \& Jorge, 1990). Embora esta serpente tenha sido registrada como uma das cinco mais abundantes de uma área de cerrado próxima à Cuia-

\section{Agradecimentos}

Os autores agradecem à médica Coordenadora do Ciave, Maria de Los Angeles Castro Garcia, por permitir o acesso aos dados do Centro e à Coordenadora do Normat, pelas facilidades de acesso à coleção. Agradecem ainda à herpetóloga Cristine Strüssmann, pela confirmação das identificações, por parte dos dados sobre espécies da área urbana, e pelas sugestões ao manuscrito. bá (Strüssmann, 1993), na área urbana representou apenas $2 \%$ dos indivíduos. Provavelmente, pelos seus hábitos, seja mais sensível às alterações provocadas pelo processo de urbanização, notadamente no que se refere à canalização de corpos d’água, drenagens, etc., pois sempre é avistada nas proximidades de corpos d'água (C. Strüssmann, comunicação pessoal). Tanto o grande número de acidentes ofídicos de importância médica quanto o grande número de registros de serpentes de interesse médico para os bairros periféricos parecem apontar nesta direção.

A espécie Crotal us durissus (cascavel), espécie de hábito eminentemente terrestre, está mais ativa durante a noite, embora também possa ser encontrada em atividade durante o dia, alimentando-se principalmente de roedores. Esta espécie ocorre em áreas abertas (cerrado, campos, cerradão), e na área urbana parece ocorrer nas áreas mais periféricas próximas à área rural. Dado o seu comportamento e a sua distribuição na área urbana, esta serpente tende a causar poucos acidentes. Embora sejam poucos os acidentes causados por cascavel (acidente crotálico) (Figura 6), estes merecem muita atenção, pois tendem a ser mais graves do que os acidentes botrópicos (MS, 1988).

\section{Referências}

BRAZIL, V., 1911. Defesa contra o Ophidismo. São Paulo: Pocai \& Weiss.

BUCARETCHI, F.; VIEIRA, R. J.; FERMINO, C. A.; BAVARESCO, A. P.; FONSECA, M. R. C. C.; DOUGLAS, J. L. \& ZAMBRONE, F. A. D., 1993. Acidentes por Philodryas olfersii relatório de dois casos. In: III Congresso Latino-Americano de Herpetologia, Resumos. Campinas: Instituto de Biologia da Universidade Estadual de Campinas.

CASTRO Jr., P. R., 1990. Carta Geotécnica de Cuiabá. Cuiabá: Fundação Universidade de Mato Grosso/ Prefeitura de Cuiabá. (mimeo.) 
DIXON, J. R., 1989. A Key and Checklist of the Neotropical Snake Genus Liophis with Country List and Maps. Washington: Smithsonian Herpetological Information Service Series, 79.

DIXON, J. R., 1991. Geographic variation and taxonomy of Liophis almadensis (Wagler) (Serpentes: Colubridae), and description of a new species of Liophis from Argentina and Bolivia. Texas Journal of Science, 43:225-236.

DIXON, J. R.; WIEST Jr., J. A. \& CEI, J. M., 1993. Revision of the Neotropical snake genus Chironius Fitzinger (Serpentes, Colubridae). MonogafieMuseo Regionale di Scienze Naturali, XIII:1-279.

FREITAS, J. C., 1991. Nomenclatura em toxinonologia, relações com a comunicação química entre organismos e propriedades biológicas das toxinas. Memórias do Instituto Butantan, 53:191-195.

GUARIM NETO, G., 1991. Diagnóstico Florístico e Faunístico da Cidade de Cuiabá. Cuiabá: Relatório Final do Convênio Fundação Universidade de Mato Gosso/ Prefeitura de Cuiabá.

KOUYOUMDJIAN, J. A. \& POLIZELLI, C., 1989. Acidentes ofídicos causados por Bothrops moojeni: correlação do quadro clínico com o tamanho da serpente. Revista do Instituto de Medicina Tropical, 31:84-90.

MARTINS, M., 1994. História Natural e Ecologia de uma Taxocenose de Serpentes de Mata na Região de Manaus, Amazônia Central, Brasil. Tese de Doutorado, Campinas: Instituto de Biociências/ Universidade Estadual de Campinas.

MAITELLI, G. T., 1994. Uma Abordagem Tridimensional de Clima Urbano em Área Tropical Continental. O Exemplo de Cuiabá - MT. Tese de Doutorado, São Paulo: Faculdade de Filosofia e Ciências Humanas/Universidade de São Paulo.

MINTON Jr., S. A., 1974. Venom Diseases. American Lectures Series, 937. Springfield: Charles C. Thomas.

MS (Ministério da Saúde), 1988. Manual de Diagnóstico e Tratamento de Acidentes Ofídicos. Brasília: Centro de Documentação do Ministério da Saúde.

MS (Ministério da Saúde), 1989. Acidentes Ofídicos. Contribuição ao Estudo da Morbidade. Brasília: Secretaria Nacional de Ações Básicas de Saúde.

MYERS, C. W. \& CADLE, J. E., 1994. A new genus for South American snakes related to Rhadinaea obtusa Cope (Colubridae) and resurrection of Tae niophalus Cope for the "Rhadinaea" brevi rostris group. American Museum Novitates, 3102:1-33.
PETERS, J. A. \& DONOSO-BARROS, R., 1970. Cataloque of the neotropical squamata. Part I. Snakes. Bulletin of the United States Natural Museum, 297:1-347.

RIBEIRO, L. A. \&JORGE, M. T., 1990. Epidemiologia e quadro clínico dos acidentes por serpentes Bothrops jararaca adultas e filhotes. Revista do Instituto de Medicina Tropical, 32:436-442.

ROSS, J. L. S. \& SANTOS, L. M., 1982. Geomorfologia. In: Proj eto RADAMBRASIL, Fol ha Cuiabá CD 21. vol. 26, (Ministério das Minas e Energia, org.). pp. 222, Brasília: Ministério das Minas e Energia.

SAZIMA, I., 1988. Um estudo da biologia comportamental da jararaca, Bothrops jararaca, com uso de marcas naturais. Memórias do Insituto Butan$\tan$, 50:83-89.

SAZIMA, I., 1989. Comportamento alimentar da jararaca, Bothrops jararaca: encontros provocados na natureza. Ciência eCultura, 41:500-505.

SAZIMA, I., 1991. Natural history of the jararaca pitviper, Bothrops jararaca, in southeastern Brazil. In: Biology of Pitvipers (J. A. Campbell \& E. D. Brodie Jr., eds.), pp. 102-127, Tyler: Selva.

SAZIMA, I. \& HADDAD, C. F. B., 1992. Répteis da Serra do Japi: notas sobre história natural. In: História Natural da Serra do Japi : Ecologia e Preservação deuma Área Florestal no Sudeste do Brasil (L. P. C. Morellato, org.), pp. 28-49, Campinas: Editora da Universidade Estadual de Campinas/Fundação de Apoio à Pesquisa do Estado de São Paulo.

SI LVA, M. V. \& BUONATO, M. A., 1983/84. Relato clínico de envenenamento humano por Philodryas olfersii. Memórias do Instituto Butantan, 47/ 48: 121-126.

STRÜSSMANN, C., 1992. Serpentes do Pantanal de Poconé, Mato Grosso: Composição Faunística e Ecologia Comparada. Dissertação de Mestrado, Campinas: Instituto de Biociências/Universidade Estadual de Campinas.

STRÜSSM ANN, C., 1993. Riqueza, abundância relativa e distribuição de espécies de serpentes ao longo da Rodovia MT-060, nos cerrados de Mato Grosso. III Congresso Latino-Americano de Herpetologia, Resumos. Campinas: Universidade Estadual de Campinas.

THOMAS, R. A., 1976. A Revision of the South American colubrid snake genus Philodryas Wagler, 1830. Ph.D. Thesis, College of Texas A. \& M. University.

WHO (World Health Organization). 1981. Progress in the characterization of venoms and standardization of antivenoms (WHO offset Publication, 58). Geneva: WHO. 